LETTERS TO THE EDITOR.

[The Editor does not hold himself responsible for opinions expressed by his correspondents. Neither ian he undertake to return, or to correspond with the writers of, rejerted manuscripts intended for this or any other part of NATURE. No notice is taken of anonymous communications.]

\section{The Food of the Rook.}

Is there not even a fallacy in the argument against this bird which is supported by a note in NATURE of June 6, p. 27I? You say that because 52 per cent. of the rook's food is injurious, 19.5 per cent. neutral, and 28.5 per cent. beneficial, therefore "it is impossible to ignore the fact that at present this bird does considerably more harm than good," even though, as you admit, 23.9 per cent. of the rook's food consists of injurious insects.

Is it not possible that if these injurious insectsthey doubtless consist of many species--had been left unconsumed by the rook, they might have so multiplied that their total depredation upon man's food supply would have considerably exceeded the 52 per cent. of foodstuffs which the bird consumes directly?

As a method more likely to restore the balance of Nature than the indiscriminate destruction of certain species of birds, the rook included, I would suggest a strict preservation of all our birds of prey; and now that game-preservation has to take second place to food production, this would seem to be a matter for practical legislation.

Norwich, June Io. SYDNEY H. LONG.

If Dr. Long assumes that the 239 per cent of injurious insects left unconsumed might have multiplied, it is surely only fair that he should also assume that, under similar conditions, the 48.5 per cent, of cereals, potatoes, and roots would have multiplied and brought forth a hundredfold. The point at issue, however, is whether, in estimating by the volumetric method the amount of food consumed by the rook per annum the figures express equivalent or economic values. This method has so long been recognised as the only trustworthy one that it is not necessary to reassert its superiority over all others; and as McAtee has so pertinently remarked (The Auk, I912, p. 452), such "criticisms are wide of the mark, for no one claims that percentages do express economic values. They are simply convenient handles to facts, and they must be interpreted." As the result of long experience and the examination of the alimentary system of upwards of two thousand rooks, by which we have obtained the percentages referred to, viz. that of the food consumed by the rook during a whole vear, 52 per cent. is injurious, 19.5 per cent. neutral, and 28.5 per cent. beneficial, our interpretation of these figures, in the light of a long experience as to the detailed nature of the food under each heading, leads us to the conclusion that this bird does considerably more harm than good.

The advisability of practical- leģislation for the strict preservation of birds of prev and the relationship of such to game-bird preservation is a very complicated subject. All statistics, however, go to prove that the preservation of game-birds is beneficial rather than inimical to food production, and there are many other sides of the auestion which Dr. Long does not seem to have considered. THE Writer of the Note.

A Proof that any Aggregate can be Well-ordered.

Ix my letter printed in NATURE for April 4, rgis (vol. ci., p. 84), the class of direct continuations used for well-ordering should have been stated to be "comNO. 2538 , VOL. IOI] plete"-that is to say, no chain of $M$ outside the class is such that every member of this class is a segment of this new chain. The actual construction of a complete class of direct continuations can be carried out in a perfectly unique manner throughout in terms of the possible chains of $M$, without assuming that there is any chain of $M$ that exhausts $M$ itself. This construction is given in detail in a paper which will shortly appear in the Comptes rendus, and the detail of the consequences of the existence thus proved has already appeared in the Comptes rendus for April 2.

The Bourne, Basingbourne Road, Fleet, Hants, May 3I.

\section{Construction for an Approximate Quadrature of the Gircle.}

THE construction for squaring the circle given by Mr. R. E. Baynes in Nature for June 6 was described more fully by Mr. T. M. P. Hughes in the issue for April 2, I9:14, with a simple extension to the representation of the circumference.

Mr. Hughes suggested the use of a permanent setsquare of the proper angle, and it seems that the method was known earlier, for in the Science Museum at South Kensington I have seen a set-square for the purpose. I did not examine it carefully, but I believe it bore the inscription "Edward Bing, Riga, 1876." Perhaps someone else may know the history of this instrument and method.

University of Edinburgh, June 8.

There are in the Science Museum three examples of the set-square to which Mr. Smeal refers. They have been here since 1876 , in which year they were lent by the inventor, Edward Bing, a member of the staff of the Waggon Works at Riga, for exhibition in the Special Loan Collection of Scientific Apparatus. There is a short description in the third edition of the catalogue of that collection, published in $\mathrm{I} 876$, at $\mathrm{p}$. I4, and $\mathrm{I}$ have no record of any earlier published description. One of the examples is of steel and the other two of wood, the hypotenuse in each case being about $7 \frac{3}{8}$ in. long. The inventor's MS. label inside the mahogany case containing the steel set-square reads:- "Bing's Circular Square. Kreiswinkel. Equerre circulaire. Cosinus $\alpha=\sqrt{\pi / 4}$ $\left(\alpha=27^{\prime} 35^{\prime} 49^{\circ} 636^{\prime \prime}\right)$."

The Science Museum,

South Kensington, June I3. $_{3}$.

\section{INTER-ALLIED SCIENTIFIC FOOD COMMISSION.}

$\mathrm{IN}$ a recent speech $\mathrm{Mr}$. Clynes stated that the events of the last two years had revealed the necessity, not only of securing complete unity of action among the Allies, but also of basing any such action on the guiding principles laid down by science. This reoognition of the fundamental part which science should play in the successful direction of public affairs is noteworthy as coming from a member of the youngest of our political parties, and augurs well for the future of the country when this party comes to be entrusted with a responsibility commensurate with its political power. In fact, much of the success of the Ministry with which Mr. Clynes is connected may be ascribed to the adoption by Lord Rhondda of a policy based on the collective experience of 